\title{
Circulating microRNAs and their role in the immune response in triple-negative breast cancer (Review)
}

\author{
PATRICIA PIÑA-SÁNCHEZ ${ }^{*}$, HILDA-ALICIA VALDEZ-SALAZAR ${ }^{2 *}$ and MARTHA-EUGENIA RUIZ-TACHIQUÍN ${ }^{1}$ \\ ${ }^{1}$ Oncological Diseases Medical Research Unit, Oncology Hospital, \\ ${ }^{2}$ Infectious and Parasitic Diseases Medical Research Unit, Pediatrics Hospital 'Dr. Silvestre Frenk Freund', XXI \\ Century National Medical Center, Mexican Institute of Social Security (IMSS), Mexico City 06720, Mexico
}

Received October 15, 2018; Accepted July 29, 2020

DOI: $10.3892 / \mathrm{ol} .2020 .12087$

\begin{abstract}
Breast cancer (BC) is the most common type of cancer in women worldwide, and despite advances in treatments, its incidence and mortality are increasing. Therefore, it is necessary to develop new, non-invasive tests that provide more accurate diagnosis and prognosis in a timely manner. A promising approach is measuring the presence of biomarkers to detect tumors at various stages and determine their specific characteristics, thus allowing for more personalized treatment. MicroRNAs (miRNAs) serve a role in gene expression, primarily by interacting with messenger RNAs, and may be potential biomarkers for detecting cancer. They are detectable in tissues and blood, including plasma and/or serum, are stable and often tumor specific. Also, different miRNAs are associated with specific BC molecular subtypes. Triple-negative BC (TNBC) is a type of $\mathrm{BC}$ in which the primary targets for hormonal therapy are absent. It is an aggressive phenotype, which frequently metastasizes and is associated with an unfavorable prognosis. The present review focuses on circulating miRNAs in patients with TNBC, with an emphasis on their interaction with the immune response checkpoint genes PD-1, PD-L1 and CTLA4. Modulation and response of the immune system are of interest in cancer treatment due to the success of immunotherapy in the treatment of various neoplasms. Based on the findings of this literature review and the in silico analysis performed as part of this review, it is concluded that circulating hsa-miR-195 and hsa-miR-155 in TNBC interact with checkpoint genes involved in the
\end{abstract}

Correspondence to: Dr Martha-Eugenia Ruiz-Tachiquín, Oncological Diseases Medical Research Unit, Oncology Hospital, XXI Century National Medical Center, Mexican Institute of Social Security (IMSS), 330 Avenida Cuauhtémoc, Mexico City 06720, Mexico

E-mail: mertachiquin@gmail.com

${ }^{*}$ Contributed equally

Key words: microRNAs, plasma/serum, breast cancer, immune response immune response. Further analysis of the expression of these circulating miRNAs and their association with prognosis in patients with TNBC treated with immunotherapy should be assessed to evaluate their possible use as non-invasive predictive biomarkers. In addition, functional studies to analyze biologically relevant targets in the development and prognosis of TNBC, which could be therapeutic targets, are also recommended.

\section{Contents}

1. Introduction

2. miRNAs as biomarkers in $\mathrm{BC}$

3. Circulating miRNAs in BC

4. Checkpoints and miRNAs in TNBC

5. Conclusions

\section{Introduction}

Breast cancer $(B C) . \mathrm{BC}$ is a heterogeneous malignant tumor that develops in the mammary gland. It has the highest incidence and mortality rates of all types of cancer in women worldwide, with $>2,088,849$ cases and 626,679 deaths reported in 2018 , making it a primary global public health issue. The incidence of BC varies greatly with geographic region, but the death rates are less variable. For example, New Zealand and Australia reported an estimated age-standardized rate (ASR per 100,000) for incidence of 92.6 and 94.5, respectively, and a death rate (ASR) of 14.2 and 12.3, respectively, whereas for Southern and Central Asia the incidence and death ASRs were 25.9 and 13.6, respectively (1). Nearly $75 \%$ of all cases and $60 \%$ of deaths occur in high- and upper-middle-income countries. However, mortality rates among women $<50$ years old are higher in countries with low and lower-middle income compared with countries with high or upper-middle income (2). Regarding 5-year survival rates, there are significant differences between regions; in the United States and Australia the 5-year survival rate is estimated to be $90 \%$, whereas in South Africa it is $40 \%$ (3). Not only are there epidemiological differences in BC, there are also differences in tumor biology that affect the prognosis and response to treatment. 
Classification of $B C . \mathrm{BC}$ is a highly heterogeneous disease that has been classified according to a variety of characteristics, such as histology, anatomical features (Tumor-Node-Metastasis staging system) (4), tumor grade and molecular traits. BC is classified histologically as non-invasive (in situ) or invasive by location. At present, 21 histological subtypes have been described, the most frequently occurring of which are ductal carcinoma (40-75\% of cases) and lobular carcinoma (5-15\% of cases) (5). BC is not only classified according to its clinical and histopathological characteristics, but also according to its prognosis and molecular traits (4).

In 2000, Perou et al (6) proposed the first molecular classification of BC based on global expression profiles. They described the subtypes estrogen receptor $(\mathrm{ER})^{+} /$luminal-like, human epidermal growth factor receptor 2 (HER2) enriched, basal-like and normal-like (Table I). Subsequent studies confirmed the molecular subgroups, and new prognostic tests based on messenger RNA (mRNA) expression profiles in tumor tissue, such as MammaPrint ${ }^{\circledR}$, Oncotype Dx ${ }^{\circledR}$, PAM50 ${ }^{\circledR}$, Endopredict $^{\circledR}$ and 2-gene Breast Cancer Index, became available. These tests, however, are used for specific cases; for example, MammaPrint ${ }^{\circledR}$ is used for women in stage I and II $\mathrm{ER}^{+}$to predict recurrence at 10 years (7). However, the use of expression profile tests has not been applied on a larger scale due to technical and financial limitations. As a consequence, immunohistochemical (IHC) biomarkers are used as an alternative method for classification (8). Ad hoc international agreements have developed and ratified guidelines for BC evaluation and classification according to the expression levels of the following biomarkers: Estrogen receptor, progesterone receptor, HER 2 and $\mathrm{Ki}-67$ proliferation factor (Table I) (9). IHC biomarkers are essential for classification, prognosis and therapeutic decision-making in BC. Tumors that are positive for hormonal receptors as well as those that express high levels of HER2 are susceptible to specific therapies and represent $\sim 85 \%$ of all cases of BC. However, $\sim 15 \%$ of BC cases are classified as triple-negative BC (TNBC) as they do not express hormonal receptors or have high expression levels of HER2; thus endocrine therapy and trastuzumab are inefficient treatments for this subgroup (10). In recent years, TNBC has been the subject of numerous clinical and biological studies with the aim of improving understanding of these tumors and improving patient outcomes.

Clinical and molecular characteristics of TNBC. TNBC is a subgroup of heterogeneous tumors that primarily affects younger patients of African and Hispanic ethnicity, although it has also been reported in patients of Asian origin (11). These tumors are generally larger than non-TNBC types, and patients who present with affected lymph nodes at diagnosis have a high risk of metastasis and mortality. The histological traits of these tumors include high grade and a high mitotic index, although low grade triple-negative neoplasms have been reported (12). Several studies have shown lower 5-year survival rates in patients with TNBC compared with patients with other molecular subtypes of BC (75 vs. 93\%). Hispanic patients with TNBC have lower survival rates compared with those with other BC subtypes (62 vs. 80\%) (13). It has been reported that $28-36 \%$ of patients with TNBC benefit from neoadjuvant chemotherapy based on a combination of anthracyclines, alkylating agents and microtubule inhibitors (14). Gass et al (15) observed higher rates of complete pathological response (cPR) to taxane-platinum combinations (50\%), compared with anthracycline-taxane combinations $(41.8 \%)$ in patients with TNBC. The cPR rate in BRCA1/2-negative patients with TNBC to neoadjuvant therapy based on carboplatin is higher than that in HER2-positive patients with BC (16). Recurrence occurs, on average, after 1.6 years, with a recurrence rate of $25 \%$ in patients with TNBC, $74 \%$ of which is systemic recurrence (17). Among recurrent cases, 51\% have distant metastases in multiple sites, most frequently in the lung (56\%), bone (44\%), liver (30\%) and brain (22\%) (17). This highlights the importance of identifying biomarkers to predict recurrence and metastasis as this may improve treatments and prognoses, thus increasing survival rates and times. There is a need for molecular analysis that recognizes alterations that may impact prognosis and prediction, and enables improvements and/or modifications in therapy to be made in a timely manner.

The first biological characteristic described for TNBC was its association with mutations in the BRCA genes, particularly BRCA1 (15). Subsequently, various clinical studies assessed the benefits of immunotherapy, particularly the use of programmed cell death 1 ligand 1 (PD-L1)/programmed cell death 1 (PD-1) inhibitors, in patients with TNBC (18). Although the rate of response to treatment in patients selected for PD-L1/PD-1 expression was greater (20-30\%) than that for non-selected patients $(10 \%)$, the cPR results for monotherapy were improved when immunotherapy was used in combination with other therapeutic agents (18). Improved clinical, pathological and molecular characterization of TNBC is essential to identify the cases in which specific systemic and/or targeted treatments may potentially benefit the patient.

To determine the molecular characteristics of TNBC, Lehmann et al (19) analyzed the gene expression profiles of 3,247 cases of TNBC. They identified six subgroups, which comprised two basal-like subgroups, in addition to immunomodulatory (IM), mesenchymal (M), mesenchymal stem-like and luminal androgen receptor (LAR) subgroups. In further analyses of inflammatory infiltrate and stromal cells, TNBC tumors were stratified into four categories: Basal 1, basal 2, M and LAR (Table II) (20). These molecular subgroups exhibit differences in cPR to neoadjuvant anthracycline-taxane chemotherapy. In particular, significant differences were identified in the cPR for basal type 1 tumors compared with the other subgroups (41 vs. 31\%; Table II). Similarly, Burstein et al (21) identified four molecular subtypes according to expression profiles and copy-number variations, which they termed LAR, M, basal-like immunosuppressor (BLIS) and basal-like immunoactivator (BLIA). Additionally, they found that the BLIA subtype was associated with improved overall survival compared with the other subtypes, whereas BLIS was associated with the worst overall survival. Furthermore, they identified potential therapeutic targets, which included androgen receptor, mucin 1, platelet-derived growth factor receptor and PD-1. The clinical, pathological and molecular heterogeneity of TNBC requires comprehensive analysis to achieve a consensus regarding its classification in order to determine suitable therapies and improve its prognosis. 
Table I. Characteristics of molecular subtypes of breast cancer.

\begin{tabular}{|c|c|}
\hline Molecular subtype & $\begin{array}{l}\text { Immunohistochemical } \\
\text { classification }\end{array}$ \\
\hline Luminal A & $\mathrm{ER}^{+}$and/or $\mathrm{PR}^{+}, \mathrm{HER}^{-}, \mathrm{Ki} 67<14 \%$ \\
\hline Luminal B & $\begin{array}{l}\mathrm{HER} 2^{-}, \mathrm{ER}^{+} \text {and/or } \mathrm{PR}^{+}, \mathrm{Ki} 67 \geq 14 \% \text {; or } \\
\mathrm{HER}^{+}, \mathrm{ER}^{+} \text {and/or } \mathrm{PR}^{+} \text {, any Ki67 }\end{array}$ \\
\hline HER2 & $\mathrm{ER}^{-}, \mathrm{PR}^{-}, \mathrm{HER}^{+}$ \\
\hline Triple-negative & $\mathrm{ER}^{-}, \mathrm{PR}^{-}, \mathrm{HER}^{-}$ \\
\hline Basal-like & $\mathrm{ER}^{-}, \mathrm{PR}^{-}, \mathrm{HER}^{-}$ \\
\hline
\end{tabular}

ER, estrogen receptor; PR, progesterone receptor; HER2, human epidermal growth factor receptor 2. Taken and modified from St. Gallen Consensus 2011 (9).

Another factor that has been the subject of various studies of BC is non-coding RNA, particularly microRNAs (miRNAs). However, non-coding RNAs are not considered in current molecular classification systems of TNBC despite their regulatory importance; nevertheless, numerous studies have identified miRNA signatures that may differentiate molecular subtypes (22-24).

\section{2. miRNAs as biomarkers in $\mathrm{BC}$}

miRNAs dysregulation has been shown in the majority of different types of cancer, including BC (25). Some miRNAs are upregulated, whereas others are downregulated in $\mathrm{BC}$ tissues compared with healthy tissues, which highlights their potential as biomarkers.

PubMed (https://ncbi.nlm.nih.gov/pubmed/; accessed January 10,2020 ) includes 5,351 reports regarding miRNAs in BC (search term, 'microRNA AND breast cancer'); 537 reports for 'microRNA AND triple negative breast cancer'; 207 reports for 'circulating microRNA AND breast cancer'; and 21 reports for 'circulating microRNA AND triple negative breast cancer'. The present review highlights the findings of various studies on miRNAs and $\mathrm{BC}$, with a focus on circulating miRNAs and TNBC.

miRNAs. miRNAs are small RNAs that are primarily considered to function as regulators of mRNAs. miRNAs interact with complementary sequences in the $3^{\prime}$ or $5^{\prime}$ untranslated regions (UTRs) of mRNAs, thus blocking translation or promoting the breakdown of that mRNA (26). A single miRNA can interact with and regulate a wide range of mRNAs (27). Other noncanonical functions of miRNAs include increasing the translation of target mRNAs by recruiting protein complexes and increasing ribosome biogenesis (28). Since the discovery of miRNAs (29), our understanding of the regulation of gene expression and its role in a wide variety of biological functions has improved greatly.

The first miRNA repository (version 1.0) was published in December 2002 and included 218 precursor and mature miRNAs from five different species (http://www.mirbase. $\operatorname{org} /$ ). The most recent database (version 22) contains
271 organisms with 48,860 mature miRNAs. For humans, 1,917 precursor sequences and 2,654 mature sequences have been reported (30).

Structural and functional characterization of miRNAs has prompted investigation of their roles in the development and progression of various types of cancer. Several studies have identified expression profiles of miRNAs in cancer and healthy tissues that suggest they function as oncogenes (onco-miRNAs) or tumor suppressor genes $(25,31)$. It is estimated that $>50 \%$ of miRNAs are contained within fragile areas or genomic regions associated with cancer (32), and $\sim 60 \%$ of coding mRNAs are regulated by miRNAs (33).

miRNAs in TNBC. Interest in the molecular characterization of TNBC has more recently included miRNAs. The first report to indirectly include profiles of miRNA expression in BC, including TNBC, was published in 2008 (34). hsa-miR-210 was determined to be associated with a poor prognosis (34). A search of PubMed (accessed February 24, 2019; search term 'breast AND cancer AND triple negative AND miRNA) found 548 reports on this topic. The most notable of these are included in Tables III (23,35-62) and IV (36,37,46,63-65), where there is a brief description of some of the most representative meta-analyses.

Li et al (36) analyzed 1,299 BC tumours from the METABRIC database (https://www.cbioportal.org/study/summary?id=brca metabric) and compared TNBC $(\mathrm{n}=204)$ with non-TNBC $(\mathrm{n}=1,095)$ samples to identify miRNAs associated with survival. They identified 376 differentially expressed miRNAs, of which only 10 showed a statistically significant association with poor survival in patients with TNBC: hsa-miR-301b, hsa-miR-181a-2-3p, hsa-miR-105-5p and hsa-miR-93-3p were upregulated; whereas hsa-miR-7-1-3p, hsa-miR-135a, hsa-miR-628-5p, hsa-miR-638, hsa-miR-3173 and hsa-miR-4245 were downregulated in TNBC. The authors suggested the use of these miRNAs as survival biomarkers exclusive to TNBC, as no association was found for these miRNAs in non-TNBC samples. To validate this hypothesis, an analysis was conducted using a different dataset (Gene Expression Omnibus; ID, GSE40267), confirming the upregulation of four miRNAs: hsa-miR-301b, hsa-miR-181a-2-3p, hsa-miR-105-5p and hsa-miR-93-3p, but the downregulation of only one miRNA, hsa-miR-628-5p. Functional analysis confirmed the roles of hsa-miR-93-3p and hsa-miR-105 in chemoresistance to cisplatin. It was suggested that this resistance is caused by activation of the $\mathrm{Wnt} / \beta$-catenin pathway, via regulation of secreted frizzled-related protein 1 (36).

Naorem et al (65) identified 255 differentially expressed miRNAs between TNBC and non-TNBC tumors, of which 125 were upregulated and 130 were downregulated in TNBC compared with in non-TNBC. The miRNAs with the highest levels of expression were hsa-miR-135b-5p, hsa-miR-18a-5p, hsa-miR-9-5p and hsa-miR-522-3p. By contrast, hsa-miR-190b and hsa-miR-449a were the most significantly downregulated miRNAs. hsa-miR-522-3p had the highest number of predicted target genes with 1,618, and hsa-miR-449a had the least with 500. In a pathway enrichment analysis, the Wnt and RAS/MAPK signaling pathways were the most frequently identified pathways. Activation of the Wnt/ $\beta$-catenin pathway is associated with poor prognosis in $\mathrm{BC}$ and this activation may be independent of CTNNB1 mutations (66). Activation 
Table II. Molecular classification of triple-negative breast cancer.

\begin{tabular}{llcc}
\hline Type & \multicolumn{1}{c}{ Characteristics } & Distribution (\%) & cPR (\%) \\
\hline Basal 1 & High grade, early stages & 35 & 41 \\
Basal 2 & Growth factors, myoepithelial markers, metaplastic carcinomas & 22 & 18 \\
Luminal androgen receptor & Older women, positive lymph nodes, bone metastasis, infiltrating & 16 & 29 \\
& lobular carcinomas & 25 & 38 \\
Mesenchymal & Pulmonary metastasis, metaplastic carcinomas & 2 & NA \\
Unclassified & NA & 25 \\
\hline
\end{tabular}

Characteristics are reflective of the molecular type; they are those most commonly presented for the specified type, but not exclusive for it. Modified from Lehmann et al (20). NA, not applicable; cPR, complete pathological response in cohort treated with neoadjuvant chemotherapy.

of the RAS/MAPK pathway has been associated with reduced lymphocyte infiltration in TNBC, and also predicts the response to immune checkpoint inhibitors (67).

Studies based on information available in public databases have focused on the interactions and competition networks of various types of RNA. Koduru et al (63) analyzed different small non-coding RNAs and long non-coding RNA (lncRNAs) using next generation sequencing data from TNBC and healthy tumor adjacent tissues. They identified 55 differentially expressed miRNAs, of which hsa-miR-301b, hsa-miR-183, hsa-miR-18a, hsa-miR-3074 and hsa-miR-96 were upregulated in TNBC compared with the adjacent non-tumor tissue. By contrast, hsa-miR-122, hsa-miR-204, hsa-miR-135a-2, hsa-miR-139 and hsa-miR-215 were downregulated in TNBC compared with the adjacent non-tumor tissue. Changes in the levels of expression associated with clinical stage were also assessed, and six miRNAs (hsa-miR-135a-2, hsa-miR-16-1, hsa-miR-215, hsa-miR-301b, hsa-miR-486 and hsa-miR-517b) were found to be associated with stages I-III. The number of dysregulated miRNAs was greater in the earlier stages of cancer, dysregulated small non-coding RNAs were enriched in chromosomes 14, 11 and 1, and the most commonly affected pathway was the TGF- $\beta$ signaling pathway (63).

Yuan et al (37) also identified RNAs that were differentially expressed between TNBC and the healthy adjacent tissue, and found that hsa-miR-105-1, hsa-miR-519a-1, hsa-miR-105-2, hsa-miR-767 and hsa-miR-516a-1 were upregulated, while hsa-miR-486-1, hsa-miR-486-2, hsa-miR-4732, hsa-miR-139 and hsa-miR-451a were downregulated. They later correlated five modules with a weighted gene co-expression network analysis, including 22 hub genes, and identified 11 miRNAs associated with those hub genes. Of these miRNAs, the following were found to form an important part of a competing endogenous RNA network: hsa-miR-183, hsa-miR-9 and hsa-miR-145. The authors also identified seven upregulated RNAs, namely AKAP12, FOS, EMX2OS, MYCNOS, RP11-542B15.1, hsa-miR-9 and hsa-miR-183 that were associated with a poor prognosis, whereas another four upregulated mRNAs, namely hsa-miR-145, LINC00461, RP11-576D8.4 and RP11-496D24.2, were associated with a favorable prognosis. It is important to note that clinically relevant miRNAs were not among the top unregulated miRNAs.

Yang et al (46) constructed and analyzed an interaction network comprising miRNAs, IncRNAs and mRNAs for
TNBC using RNA-Seq data for tumors and healthy tissue from The Cancer Genome Atlas (https://cancer.gov/tcga). They identified 114 differentially expressed miRNAs. The five most significantly upregulated miRNAs were hsa-miR-105-2, hsa-miR-105-1, hsa-miR-1269a, hsa-miR-767 and hsa-miR-1269b; whereas hsa-miR-133a-2, hsa-miR-133a-1, hsa-miR-1-1, hsa-miR-1-2 and hsa-miR-133b were the most significantly downregulated genes. In addition, the upregulation of hsa-miR-135b and hsa-miR-216a expression was positively correlated with overall survival, whereas the upregulation of hsa-miR-3610 and hsa-miR-7706 expression was negatively correlated. As part of the competition analysis for endogenous RNAs (RNAs-lncRNAs, mRNA), the authors defined a panel of four lncRNAs (LINC00452, ST7-AS2, LINC00461 and LINC00517), three miRNAs (hsa-miR-145, hsa-miR-144 and hsa-miR-137), four mRNAs (EZH2, FSCN1, SOX11 and KLF4), which were validated by reverse transcription-quantitative PCR in independent samples. The expression of LINC00461 or LINC00517 was found to negatively correlate with the expression of hsa-miR-144 or hsa-miR-137, suggesting regulation by competition and a possible role of these transcripts in the development of TNBC.

A recent review of 212 reports by Piasecka et al (68) reported that several miRNAs that are dysregulated in TNBC are associated with epithelial-mesenchymal transition (EMT); some of these, hsa-miR-10b, hsa-miR-21, hsa-miR-29, hsa-miR-9, hsa-miR-221/222 and hsa-miR-373 are upregulated, whereas others, including hsa-miR-145, hsa-miR-199a-5p, hsa-miR-200 family, hsa-miR-203 and miR-205 are downregulated in TNBC. In addition, Tang et al (64) identified 48 upregulated miRNAs and 74 downregulated miRNAs in TNBC, based on data from the database of differentially expressed miRNAs in human cancers (https://www.picb.ac.cn/dbDEMC/).

Numerous studies have highlighted the importance of detecting circulating miRNAs that are unregulated in TNBC tissues, as they could be used as non-invasive biomarkers. These studies are presented in the next section.

\section{Circulating miRNAs in $\mathrm{BC}$}

Diagnostic or follow-up tests in BC require biopsies to be obtained; however, the acquisition of samples may involve overcoming certain technical difficulties, particularly regarding small lesions, such as the challenge of obtaining a sample that 


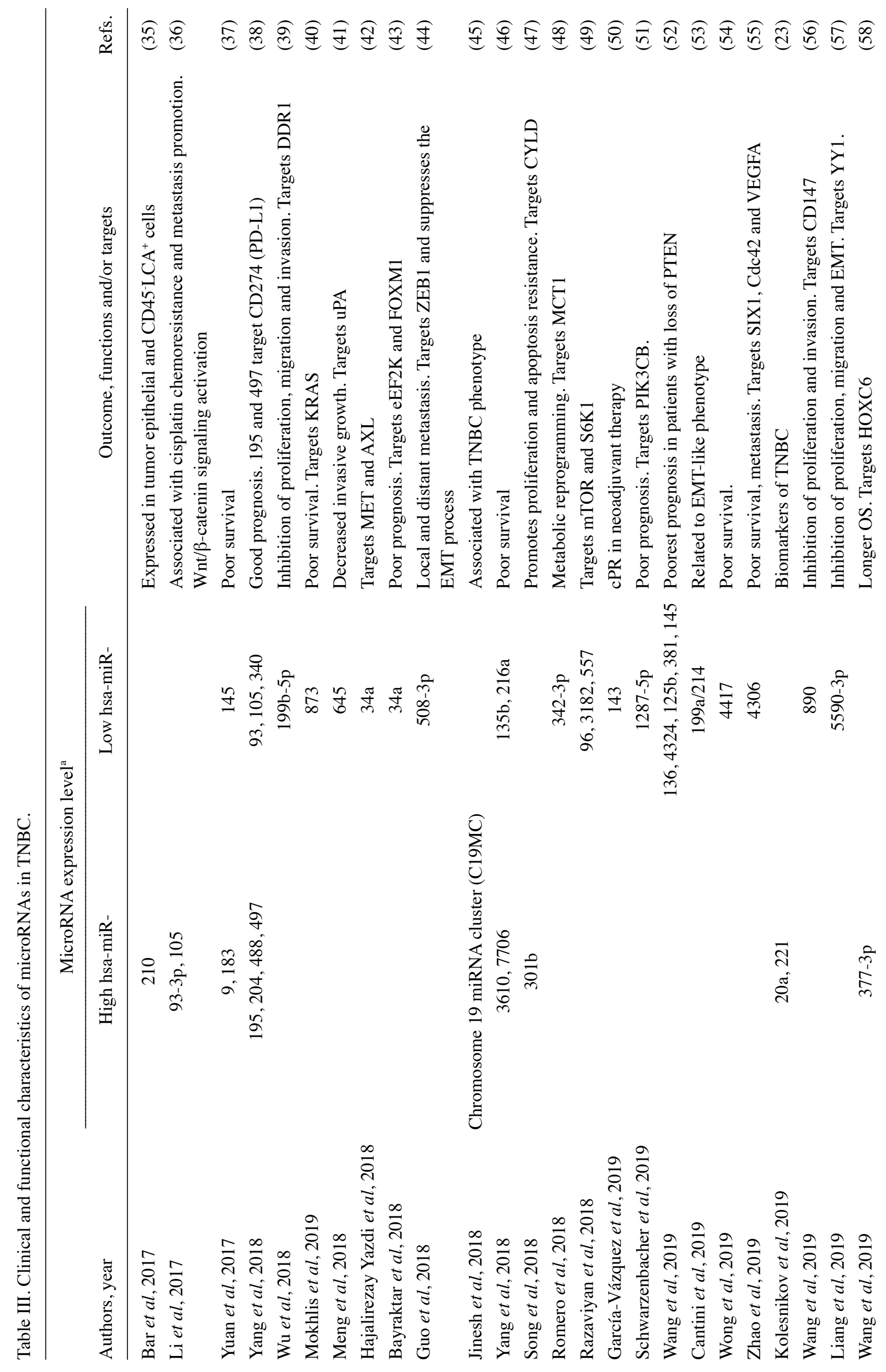


represents the entire heterogeneity of the tumor, image-guided biopsies, patient discomfort, infrastructure requirements and cost. The assessment of non-invasive biomarkers, such as those present in the circulation, would reduce these inconveniences to the patient and limitations in obtaining the samples, and may even be used preventively before clinical manifestations of the disease are observed. Another advantage of circulating biomarkers is that it would be relatively easy to obtain multiple samples over a certain time period to monitor various parameters of progression or regression of the disease following therapeutic intervention. Additionally, as miRNAs can be identified in the urine, blood, plasma, serum, saliva and feces, they are readily accessible non-invasive biomarkers for the diagnosis and prognosis of cancer and its follow-up (69).

The first study to describe the expression of circulating miRNAs in BC was published in 2008 (34). In that year, other studies assessed the presence of circulating miRNAs in patients with various types of cancer $(70,71)$. Several mechanisms for the release of circulating miRNAs have been proposed, which involve microvesicles, exosomes, circulating tumor cells and release from apoptotic bodies (72). Circulating miRNAs are stable, which makes them suitable as potential biomarkers in biological fluids. Their stability in these fluids results from protection against RNase-induced degradation by lipoproteins, argonaute protein 2 and microvesicles. They are also resistant to changes in $\mathrm{pH}$ and temperature, long storage periods and multiple freeze/thaw cycles. Additionally, as circulating miRNAs have been shown to be stable post sample collection, they can consequently be identified and quantified without the time interval between sampling and testing biasing the results $(73,74)$. One of the most relevant applications for the detection of circulating miRNAs is as an early diagnostic tool, as well as a predictive biomarker of recurrence and metastasis.

A search of PubMed found 306 publications on circulating miRNAs in PubMed, although only 25 of those were studies specific to TNBC (accessed August 5, 2019; search term, 'circulating microRNAs AND triple negative breast cancer').

Circulating miRNAs in TNBC. A summary of circulating miRNAs in TNBC is presented in Table III, and a description of the most relevant studies is presented hereinafter.

One of the first studies to analyze the expression of a circulating miRNA in patients with TNBC was published by Sahlberg et al (75). The authors first analyzed a small group of TNBC samples (10 recurrent and 10 non-recurrent cases) and their association with recurrence using the Exiqon platform, and then validated the findings in an independent cohort of 70 cases. A total of nine differentially expressed miRNAs were initially identified in the serum of patients with recurrent TNBC compared with non-recurrent TNBC (hsa-miR-18b-5p, hsa-miR-20a-5p, hsa-miR-30d-5p, hsa-miR-32-5p, hsa-miR-101-3p, hsa-miR-103a-3p, hsa-miR-107, hsa-miR-223-3p and hsa-miR-652-3p). Of these miRNAs, the upregulation of hsa-miR-18b, hsa-miR-103, hsa-miR-107 and hsa-miR-652 was found to be associated with reduced recurrence-free survival and low overall survival rates, and thus these may be specific biomarkers for predicting the outcomes of patients with TNBC (75).

Kahraman et al (76) analyzed the expression profiles of miRNAs in the blood cells of patients with basal-like TNBC 


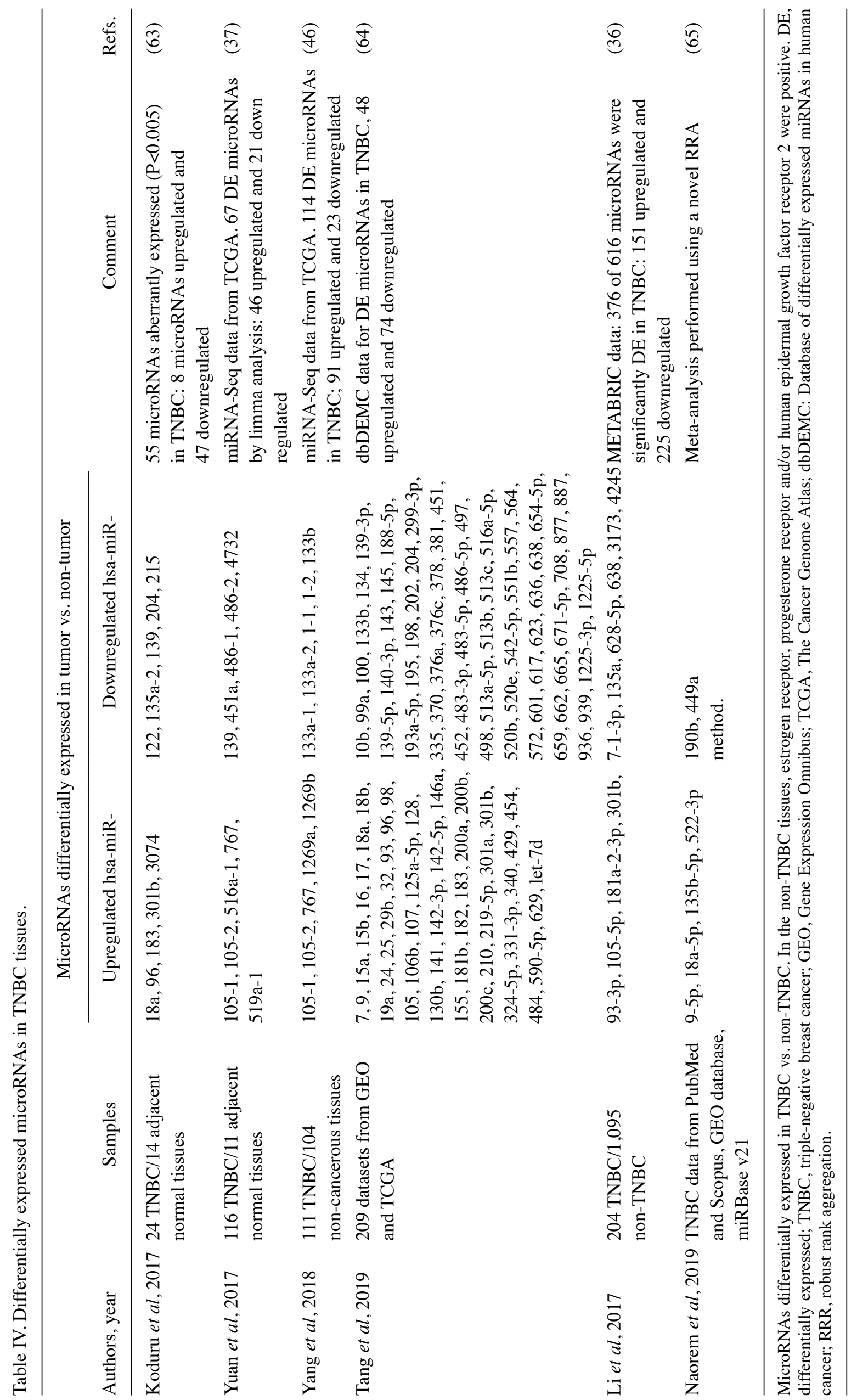


tumors (cytokeratin 5+) prior to and following neoadjuvant chemotherapy with carboplatin and paclitaxel to identify miRNAs that may predict cPR. The analysis demonstrated that although the expression levels of hsa-miR-34a-5p and hsa-miR-34b-5p in patients with TNBC prior to chemotherapy were comparable with those in healthy controls, their expression increased following neoadjuvant chemotherapy. By contrast, the expression of hsa-miR-664b-3p was reduced following therapy. Notably, the expression levels of hsa-miR-144-3p, hsa-miR-144-5p, hsa-miR-126-5p and hsa-let-7d-5p were higher in the patients with TNBC compared with the controls prior to chemotherapy, but were similar to those of the controls following therapy. Despite the differences observed in the expression levels of various miRNAs prior to and following chemotherapy, none of the miRNAs were identified to be predictive biomarkers of cPR. Nevertheless, an impact of these miRNAs on other outcomes, such as metastasis and overall survival, was observed.

Braicu et al (77) studied TNBC tumors and BC tumors positive for hormonal receptors and HER2 based on data available in The Cancer Genome Atlas, and validated their findings in plasma samples. The authors identified differentially expressed miRNAs between tumors and normal tissues, and analyzed the overlap of these differentially expressed miRNAs with those in plasma. Their discoveries included the upregulation of hsa-miR-200b, hsa-miR-200c and hsa-miR-210 in plasma and tumors, as well as the downregulation of hsa-miR-29c in plasma in patients with TNBC compared with BC positive to hormonal receptors. The hsa-miR-29c family has a role in EMT regulation and is considered an early biomarker for the prediction of metastasis (78).

According to the descriptions listed in Tables IV $(36,37,46$, 63-65) and V (36,75-92), few miRNAs have been identified consistently in different studies.

\section{Checkpoints and miRNAs in TNBC}

Immune response in $T N B C$. Immune responses in cancer have been studied for a number of decades. The first studies on this were published in the 1950s (93-95). Several studies in the 1970s described tumor-infiltrating lymphocytes (TILs) and their possible involvement in the development of neoplasms (96-98). The number of publications on cancer and immune response significantly has gradually grown over time, generating a vast field of knowledge and information on the relationship between immunity and cancer.

A seminal report highlighting the role of the immune system in cancer is that of Hanahan and Weinberg (99), in which they established evasion of immune response as one of the hallmarks of cancer.

Currently, modulation of the immune response is a major focal point in cancer treatment due to the success of immunotherapy in the treatment of malignancies, such as skin and lung cancer, which has led to the use of immunotherapy for other neoplasms, including BC (100). Similarly, the Immunoscore, which was first developed for colon cancer, has been adopted for use in other types of cancer and its inclusion in the traditional classification of cancer has been proposed for prognostic and predictive purposes (101). The Immunoscore is based on quantification of lymphocyte populations (CD3/CD45RO,
$\mathrm{CD} 3 / \mathrm{CD} 8$ or $\mathrm{CD} 8 / \mathrm{CD} 45 \mathrm{RO})$ in the marginal and central regions of tumors (92).

Several studies have described the predictive value of inflammatory infiltrates in BC, particularly for TNBC and HER 2 positive BC. Consequently, recommendations have been made for the systematic assessment of BC with TILs (102). Early studies assessed Immunoscore in BC, in addition to its contribution to pro- or antitumor activity (103). The evaluation of lymphocyte infiltrates using hematoxylin and eosin staining has been shown to have predictive and prognostic value in TNBC. It has been estimated that tumors with $>50 \%$ TILs may benefit from neoadjuvant chemotherapy, as evaluated by cPR, even when tissues from core needle biopsy specimens are used for TIL quantification (103-106). In this regard, the use of platinum-based agents improves cPR (107). The cPR has been reported to increase from 37 to $52 \%$ when platinum-based agents are used in the treatment of TNBC, with the exclusion of TNBC with mutations; however, hematological toxicity is increased (108). The impact of TILs has only been observed in TNBC and HER2-positive tumors, whereas in other molecular subtypes and low-grade tumors, the impact is small or non-existent (109).

The aforementioned molecular classification of TNBC performed by Lehmann et al (19) includes an IM subgroup, characterized by enrichment with genes associated with immune processes, including cytotoxic T-lymphocyte associated protein 4 (CTLA4), interleukin (IL)-12, natural killer cell (NK) cell and IL-7 pathways, antigen processing and presentation, NF- $\kappa \mathrm{B}$ and TNF pathways, T-cell transduction and NK-mediated cytotoxicity. A study notably observed that the overlap of genes from this subgroup with the molecular signature for medullary cancer is associated with a favorable prognosis regardless of advanced histological grade (110). However, in a later molecular classification, the number of TNBC subgroups was reduced from six to four, with removal of the IM subgroup as it resulted from enrichment with infiltrating lymphocytes (20). This posed the question of whether this molecular subtype was the expression profile of TILs or tumor cells. The authors found that TILs were more abundant in the IM subgroup than in the other subgroups, and that there was a correlation between the number of lymphocytes and the IM component of each tumor. Immune checkpoint regulators, such as CTLA4, CD274 and PDCD1, were observed amongst the genes identified in the IM subtype, and the IM subtype was associated with improved overall survival and recurrence-free survival in comparison with all other TNBC subtypes (20).

These findings have contributed to interest in the development of a mode of immunotherapy for TNBC. The first studies of immunotherapy for TNBC showed a response rate to pembrolizumab of $18 \%$, which was very similar to the initial percentage of patients classed as possessing the IM subtype $(20 \%)(18,103)$. Clinical trials using immunotherapy for the treatment of TNBC have been reviewed by Nathan and Schmid (111), and the US Food and Drug Administration has approved the use of atezolizumab (Tecentriq,Genentech/Roche) plus the chemotherapy nab-paclitaxel (Abraxane,Celgene) as first line treatment for unresectable, metastatic, PD-L1-positive TNBC (112).

Increased immune activation through interferon type I (IFN-I) signaling has been shown to increase the efficacy of 


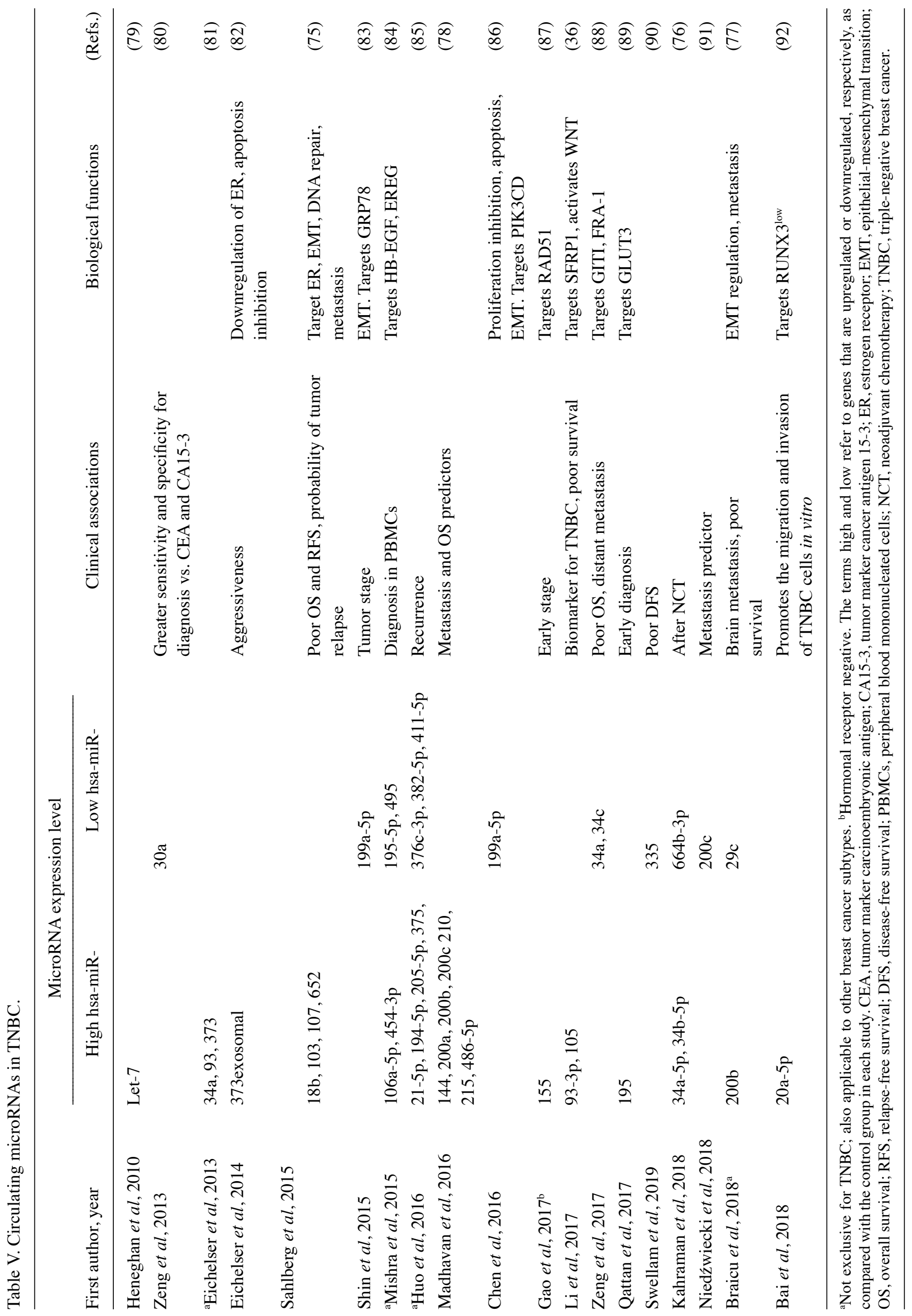


anti-PD-1 immunotherapy (113). Thus, the stratification of patients with the IM subtype and/or a high rate of TILs may help to identify patients for whom checkpoint inhibitors would be more effective.

Based on the success of immunotherapy in melanoma and lung cancer, the association between miRNAs and the immune response in $\mathrm{BC}$ is worthy of consideration, particularly with regard to the use of checkpoint inhibitors (114).

PD-1 and circulating miRNAs in TNBC. PD-1 is a cell surface protein coded for by the PDCD1 gene; it belongs to the immunoglobulin superfamily and the CD28 family of proteins. It is expressed in antigen-specific effector T cells and memory $\mathrm{T}$ cells. When it binds to its ligands (PD-L1 or PD-L2), it suppresses T-cell proliferation, the production of cytokines such as IFN- $\gamma$ and cytotoxic activity, thus resulting in immunosuppression and immunotolerance. The level of PD-1 expression in T cells is regulated by the inflammatory response and infection. PD-L1 is expressed in a variety of cell types and tissues such as solid or hematologic neoplasms; when PD-L1 is expressed in cancer cells it suppresses immunosurveillance. Consequently, various drugs have been developed to counter these effects (115).

The molecular mechanisms that direct the regulation of PD-1 expression, including cis-DNA regulatory elements, transcription factors, epigenetic regulation and changes in DNA methylation patterns and histone modifications, have been described (116); nevertheless, how miRNA-mediated regulation occurs remains largely unknown. The miRDB database (http://mirdb.org) predicts $61 \mathrm{miRNAs}$ that could potentially regulate PDCD1. Based on the miRNAs predicted to bind to the PDCD1 gene in two databases (miRDB and TargetScan version 7.2; http://www.targetscan.org; accessed June 25, 2019), we found that the circulating miRNA hsa-miR-195-5p, previously detected in TNBC, was a likely candidate as a regulator of PDCD1 expression (target score 76, context score percentile 86).

The downregulation of hsa-miR-195-5p has previously been described in the peripheral blood mononuclear cells of patients with TNBC; however, only a limited number of patients was included in this analysis (84); by contrast, Qattan et al (89) observed the upregulation of hsa-miR-195 in patients with TNBC in a study with a larger number of samples. However, Yang et al (38) found that the higher levels of hsa-miR-195 in BC were associated with improved prognosis. Nonetheless, PD-L1 has been identified as the target of hsa-miR-195.

PD-L1 and circulating miRNAs in TNBC. PD-L1 is a cell membrane protein that binds to PD-1 on effector T cells and transduces immunosuppressor signals. Expression of PD-L1 on the surface of tumor cells is critical for these cells to escape immunosuppression (117).

Based on the data in Table V and PL-D1 as the checkpoint gene for immune response, we performed an in silico analysis using DIANA-Tools (http://diana.imis.athena-innovation.gr/DianaTools/index.php?r=site/page \&view=software) and miRTarBase v7.0 (http://mirtarbase.mbc.nctu.edu. tw/php/index.php). The following results were obtained: PD-L1 gene is regulated by several miRNAs and has 20 conserved target sites for hsa-miR-140-3p.2, hsa-miR-382-3p*, hsa-miR-320c,
hsa-miR-320d, hsa-miR-4429, hsa-miR-320b, hsa-miR-320a, hsa-miR-377-3p, hsa-miR-20b-5p, hsa-miR-519d-3p, hsa-miR-106b-5p, hsa-miR-93-5p*, hsa-miR-526b-3p, hsa-miR-17-5p, hsa-miR-106a-5p*, hsa-miR-20a-5p*, hsa-miR-142-5p, hsa-miR-5590-3p, hsa-miR-653-5p and hsa-miR-155-5p* (TargetScan version 7.2; http://www. targetscan.org/vert_72/; accessed on June 25, 2019), as well as poorly conserved target sites for $>900$ hsa-miRNAs.

A study examining the effect of PD-L1 expression in human dermic lymphatic endothelial cells (HDLECs) has been conducted, in which miRNA-mediated regulation of the PD-L1 gene was observed (118). In that study, the treatment of HDLECs with IFN- $\gamma$ and TNF- $\alpha$ proinflammatory cytokines synergistically upregulated PD-L1, and altered the expression of several miRNAs that are able to reduce the expression of PD-L1. The miRNA found to be the most strongly upregulated was hsa-miR-155, which serves a key role in the immune system and cancer. Furthermore, the 3'-UTR of PD-L1 was demonstrated to have two functional binding sites for hsa-miR-155, and endogenous hsa-miR-155 was shown to control the kinetics and PD-L1 levels induced by treatment with IFN- $\gamma$ and TNF- $\alpha$. Similar findings in dermal fibroblasts confirm that a IFN- $\gamma$ and TNF- $\alpha$-induced hsa-miR-155/PD-L1 pathway is not exclusive to HDLECs. These results show that hsa-miR-155 contributes to the inflammation-induced control of PD-L1 expression in primary cells (118).

There are various studies that mention hsa-miR-155; a search of PubMed (accessed January 10, 2020) found 191 reports for 'miR-155 AND breast cancer'; 22 reports for 'miR-155 AND triple negative breast cancer'; and 3 reports for 'circulating miR-155 AND triple negative breast cancer'. Together, these studies demonstrate the well-acknowledged role of hsa-miR-155 in the early detection, tumor initiation, and cancer development and progression of $\mathrm{BC}(81,87,119)$.

CTLA4 and miRNAs in TNBC. CTLA4 is a transmembrane type 1 protein with 223 amino acids (120) coded for by the CTLA4 gene. It belongs to the immunoglobulin receptor superfamily of proteins, which also includes CD28, ICOS, PD-1, BTLA and TIGIT (121). CTLA4, PD-1, BTLA and TIGIT are negative regulators that are crucial to $\mathrm{T}$-cell mediated immunity $(120,121)$.

In T cells, CTLA4 and CD28 bind to the same ligands (CD80 and CD86) on antigen-presenting cells, but have opposing effects; the interaction of CTLA4 with its ligands inhibits the T-cell response, whereas when CD28 binds to its ligands the T-cell response is activated. CTLA4 has greater affinity for CD80/CD86 than does CD28 (122).

The CTLA4 gene is regulated by several miRNAs and has highly conserved target sites for hsa-miR-155-5p, hsa-miR-496.1 and hsa-miR-142-3p.2, in addition to $>400$ poorly conserved target sites (based on DIANA-miRPath and miRTarBase; accessed September 15, 2017). Of those highly conserved miRNAs, hsa-miR-155 is known to be a circulating hsa-miRNA in TNBC (87).

\section{Conclusions}

Circulating miRNAs are molecules with significant diagnostic, prognostic and even predictive potential as biomarkers 
for cancer, due to the relative ease and non-invasive means by which they can obtained. Nevertheless, it is necessary to standardize pre-analytical and analytical details to obtain results that have greater reproducibility, specificity and sensitivity, and to improve patient selection. hsa-miR-195 has been detected in the circulation and interacts with immune checkpoint molecules, as shown by the predictive analysis that identified PDCD1 as a potential target, and its regulation of PD-L1 has been demonstrated. Similarly, hsa-miR-155 also interacts with checkpoint genes involved in the immune response and has been reported to be a circulating miRNA during the early stages of TNBC. Analyzing the expression of these circulating miRNAs in greater detail is thus suggested, as well as their association with clinical responses in patients with TNBC treated with immunotherapy, to assess their potential role as predictive non-invasive biomarkers. Further studies of miRNA-mRNA-protein interactions and the signaling and/or metabolic pathways in which these miRNAs participate are also required.

\section{Acknowledgements}

The authors would like to thank Miss Alejandra García-Bejarano and Mr. Brian-Alexander Cruz-Ramírez, both from the Oncological Diseases Medical Research Unit, Oncology Hospital, XXI Century National Medical Center, Mexican Institute of Social Security (IMSS) (Mexico City, Mexico), for their technical assistance.

\section{Funding}

The present study received support from Coordinación de Investigación en Salud and Fondo de Investigación en Salud-Instituto Mexicano del Seguro Social (grant no. FIS/IMSS/PROT/G17-2/1748). During the development of this work, PPS received a scholarship from Fundación IMSS A.C.

\section{Availability of data and materials}

Not applicable.

\section{Authors' contributions}

PPS and HAVS wrote, edited and critically revised the manuscript. MERT was responsible for manuscript design, obtaining financial support, as well as critical revision, editing and writing of the manuscript. All authors read and approved the final manuscript. They also agree to be accountable for all aspects of the work while ensuring that questions related to the accuracy or integrity of any of its parts are appropriately investigated and resolved.

\section{Ethics approval and consent to participate}

Not applicable.

\section{Patient consent for publication}

Not applicable.

\section{Competing interests}

The authors declare that they have no competing interests.

\section{References}

1. Ferlay J, Ervik M, Lam F, Colombet M, Mery L, Piñeros M, Znaor A, Soerjomataram I and Bray F: Global cancer observatory: Cancer today. Lyon, France: International Agency for Research on Cancer. Available from: https://gco.iarc.fr/today. Accessed April 29, 2019.

2. Bellanger M, Zeinomar N, Tehranifar P and Terry MB: Are global breast cancer incidence and mortality patterns related to country-specific economic development and prevention strategies? J Glob Oncol 4: 1-16, 2018.

3. Allemani C, Matsuda T, Di Carlo V, Harewood R, Matz M, Nikšić M, Bonaventure A, Valkov M, Johnson CJ, Estève J, et al: Global surveillance of trends in cancer survival 2000-14 (CONCORD-3): Analysis of individual records for 37513025 patients diagnosed with one of 18 cancers from 322 population-based registries in 71 countries. Lancet 391: 1023-1075, 2018.

4. Amin MB, Edge S, Greene F, Byrd DR, Brookland RK, Washington MK, Gershenwald JE, Compton CC, Hess KR, Sullivan DC, et al (eds): American Joint Committee on Cancer: Cancer Staging Manual AJCC. 8th edition. Springer, New York, NY, 2017.

5. Makki J: Diversity of breast carcinoma: Histological subtypes and clinical relevance. Clin Med Insights Pathol 8: 23-31, 2015.

6. Perou CM, Sørlie T, Eisen MB, van de Rijn M, Jeffrey SS, Rees CA, Pollack JR, Ross DT, Johnsen H, Akslen LA, et al: Molecular portraits of human breast tumours. Nature 406: $747-752,2000$

7. Vieira AF and Schmitt F: An update on breast cancer multigene prognostic tests-emergent clinical biomarkers. Front Med (Lausanne) 5: 248, 2018.

8. Blows FM, Driver KE, Schmidt MK, Broeks A, van Leeuwen FE Wesseling J, Cheang MC, Gelmon K, Nielsen TO, Blomqvist C, et al: Subtyping of breast cancer by immunohistochemistry to investigate a relationship between subtype and short and long term survival: A collaborative analysis of data for 10,159 cases from 12 studies. PLoS Med 7: e1000279, 2010.

9. Goldhirsch A, Wood WC, Coates AS, Gelber RD, Thürlimann B and Senn HJ; Panel members: Strategies for subtypes-dealing with the diversity of breast cancer: Highlights of the St. Gallen international expert consensus on the primary therapy of early breast cancer 2011. Ann Oncol 22: 1736-1747, 2011.

10. Schneider BP, Winer EP, Foulkes WD, Garber J, Perou CM, Richardson A, Sledge GW and Carey LA: Triple-negative breast cancer: Risk factors to potential targets. Clin Cancer Res 14: 8010-8018, 2008

11. Yeh J, Chun J, Schwartz S, Wang A, Kern E, Guth AA, Axelrod D, Shapiro R and Schnabel F: Clinical characteristics in patients with triple negative breast cancer. Int J Breast Cancer 2017: $1796145,2017$.

12. Pareja F, Geyer FC, Marchiò C, Burke KA, Weigelt B and Reis-Filho JS: Triple-negative breast cancer: The importance of molecular and histologic subtyping, and recognition of low-grade variants. NPJ Breast Cancer 2: 16036, 2016.

13. Gonçalves H Jr, Guerra MR, Duarte CJR, Fayer VA, Brum IV and Bustamante Teixeira MT: Survival study of triple-negative and non-triple-negative breast cancer in a Brazilian cohort. Clin Med Insights Oncol 12: 1179554918790563, 2018.

14. Omarini C, Guaitoli G, Pipitone S, Moscetti L, Cortesi L, Cascinu $S$ and Piacentini F: Neoadjuvant treatments in triple-negative breast cancer patients: Where we are now and where we are going. Cancer Manag Res 10: 91-103, 2018.

15. Gass P, Lux MP, Rauh C, Hein A, Bani MR, Fiessler C, Hartmann A, Häberle L, Pretscher J, Erber R, et al: Prediction of pathological complete response and prognosis in patients with neoadjuvant treatment for triple-negative breast cancer. BMC Cancer 18: 1051, 2018.

16. Von Minckwitz G, Schneeweiss A, Loibl S, Salat C, Denkert C, Rezai M, Blohmer JU, Jackisch C, Paepke S, Gerber B, et al: Neoadjuvant carboplatin in patients with triple-negative and HER2-positive early breast cancer (GeparSixto; GBG 66): A randomised phase 2 trial. Lancet Oncol 15: 747-756, 2014. 
17. James M, Dixit A, Robinson B, Frampton C and Davey V: Outcomes for patients with non-metastatic triple-negative breast cancer in New Zealand. Clin Oncol (R Coll Radiol) 31: 17-24, 2019.

18. Vikas P, Borcherding $\mathrm{N}$ and Zhang W: The clinical promise of immunotherapy in triple-negative breast cancer. Cancer Manag Res 10: 6823-6833, 2018.

19. Lehmann BD, Bauer JA, Chen X, Sanders ME, Chakravarthy AB, Shyr Y and Pietenpol JA: Identification of human triple-negative breast cancer subtypes and preclinical models for selection of targeted therapies. J Clin Invest 121: 2750-2767, 2011.

20. Lehmann BD, Jovanović B, Chen X, Estrada MV, Johnson KN, Shyr Y, Moses HL, Sanders ME and Pietenpol JA: Refinement of triple-negative breast cancer molecular subtypes: Implications for neoadjuvant chemotherapy selection. PLoS One 16: e0157368, 2016.

21. Burstein MD, Tsimelzon A, Poage GM, Covington KR, Contreras A, Fuqua SA, Savage MI, Osborne CK, Hilsenbeck SG, Chang JC, et al: Comprehensive genomic analysis identifies novel subtypes and targets of triple-negative breast cancer. Clin Cancer Res 21: 1688-1698, 2015.

22. Kurozumi S, Yamaguchi Y, Kurosumi M, Ohira M, Matsumoto H and Horiguchi J: Recent trends in microRNA research into breast cancer with particular focus on the associations between microRNAs and intrinsic subtypes. J Hum Genet 62: 15-24, 2017.

23. Kolesnikov NN, Veryaskina YA, Titov SE, Rodionov VV Gening TP, Abakumova TV, Kometova VV, Torosyan MK and Zhimulev IF: Expression of micrornas in molecular genetic breas cancer subtypes. Cancer Treat Res Commun 20: 1000026, 2019.

24. Søkilde R, Persson H, Ehinger A, Pirona AC, Fernö M, Hegardt C, Larsson C, Loman N, Malmberg M, Rydén L, et al: Refinement of breast cancer molecular classification by miRNA expression profiles. BMC Genomics 20: 503, 2019.

25. Tan W, Liu B, Qu S, Liang G, Luo W and Gong C: MicroRNAs and cancer: Key paradigms in molecular therapy. Oncol Lett 15 : 2735-2742, 2018.

26. Gebert LFR and MacRae IJ: Regulation of microRNA function in animals. Nat Rev Mol Cell Biol 20: 21-37, 2019.

27. Masud Karim SM, Liu L, Le TD and Li J: Identification of miRNA-mRNA regulatory modules by exploring collective group relationships. BMC Genomics 17 (Suppl 1): S7, 2016.

28. Chang CY, Lai MT, Chen Y, Yang CW, Chang HW, Lu CC Chen CM, Chan C, Chung C, Tseng CC, et al: Up-regulation of ribosome biogenesis by MIR196A2 genetic variation promotes endometriosis development and progression. Oncotarget 7 : 76713-76725, 2016.

29. Lee RC, Feinbaum RL and Ambros V: The C. elegans heterochronic gene lin-4 encodes small RNAs with antisense complementarity to lin-14. Cell 75: 843-854, 1993.

30. Kozomara A, Birgaoanu M and Griffiths JS: miRBase: From microRNA sequences to function. Nucleic Acids Res 47D D155-D162, 2019.

31. Svoronos AA, Engelman DM and Slack FJ: OncomiR or tumor suppressor? The duplicity of microRNAs in cancer. Cancer Res 76: 3666-3670, 2016.

32. Khordadmehr M, Shahbazi R,Ezzati H, Jigari-Asl F, Sadreddini S and Baradaran B: Key microRNAs in the biology of breast cancer; emerging evidence in the last decade. J Cell Physiol 234: $8316-8326,2019$

33. Friedman RC, Farh KK, Burge CB and Bartel DP: Most mammalian mRNAs are conserved targets of microRNAs. Genome Res 19: 92-105, 2009.

34. Foekens JA, Sieuwerts AM, Smid M, Look MP, de Weerd V, Boersma AW, Klijn JG, Wiemer EA and Martens JW: Four miRNAs associated with aggressiveness of lymph node-negative, estrogen receptor-positive human breast cancer. Proc Natl Acad Sci USA 105: 13021-13026, 2008.

35. Bar I, Merhi A, Abdel-Sater F, Ben Addi A, Sollennita S, Canon JL and Delrée P: The MicroRNA miR-210 is expressed by cancer cells but also by the tumor microenvironment in triple-negative breast cancer. J Histochem Cytochem 65: 335-346, 2017.

36. Li HY, Liang JL, Kuo YL, Lee H-H, Calkins MJ, Chang HT, Lin FC, Chen YC, Hsu TI, Hsiao M, et al: miR-105/93-3p promotes chemoresistance and circulating miR-105/93-3p acts as a diagnostic biomarker for triple negative breast cancer. Breast Cancer Res 19: 133, 2017

37. Yuan N, Zhang G, Bie F, Ma M, Ma Y, Jiang X, Wang Y and Hao X: Integrative analysis of lncRNAs and miRNAs with coding RNAs associated with ceRNA crosstalk network in triple negative breast cancer. OncoTargets Ther 10: 5883-5897, 2017.
38. Yang L, Cai Y, Zhang D, Sun J, Xu C, Zhao W, Jiang W and Pan C: $\mathrm{miR}-195 / \mathrm{miR}-497$ regulate CD274 expression of immune regulatory ligands in triple-negative breast cancer. J Breast Cancer 21: 371-381, 2018

39. Wu A, Chen Y, Liu Y, Lai Y and Liu D: miR-199b-5p inhibits triple negative breast cancer cell proliferation, migration and invasion by targeting DDR1. Oncol Lett 16: 4889-4896, 2018

40. Mokhlis HA, Bayraktar R, Kabil NN, Caner A, Kahraman N, Rodriguez-Aguayo C, Zambalde EP, Sheng J, Karagoz K, Abdel Aziz AAH, et al: The modulatory role of microRNA-873 in the progression of KRAS-driven cancers. Mol The Nucleic Acids 14: 301-317, 2019

41. Meng D, Lei M, Han Y, Zhao D, Zhang X, Yang Y and Liu R: MicroRNA-645 targets urokinase plasminogen activator and decreases the invasive growth of MDA-MB-231 triple-negative breast cancer cells. Onco Targets Ther 11: 7733-7743, 2018

42. Hajalirezay Yazdi S, Paryan M and Mohammadi-Yeganeh S: An integrated approach of bioinformatic prediction and in vitro analysis identified that miR-34a targets MET and AXL in triple-negative breast cancer. Cell Mol Biol Lett 23: 51, 2018.

43. Bayraktar R, Ivan C, Bayraktar E, Kanlikilicer P, Kabil NN, Kahraman N, Mokhlis HA, Karakas D, Rodriguez-Aguayo C, Arslan A, et al: Dual suppressive effect of miR-34a on the FOXM1/eEF2-kinase axis regulates triple-negative breast cancer growth and invasion. Clin Cancer Res 24: 4225-4241, 2018.

44. Guo SJ, Zeng HX, Huang P, Wang S, Xie CH and Li SJ: MiR-508-3p inhibits cell invasion and epithelial-mesenchymal transition by targeting ZEB1 in triple-negative breast cancer. Eur Rev Med Pharmacol Sci 22: 6379-6385, 2018.

45. Jinesh GG, Flores ER and Brohl AS: Chromosome 19 miRNA cluster and CEBPB expression specifically mark and potentially drive triple negative breast cancers. PLoS One 13: e0206008, 2018.

46. Yang R, Xing L, Wang M, Chi H, Zhang L and Chen J: Comprehensive analysis of differentially expressed profiles of lncRNAs/mRNAs and miRNAs with associated ceRNA networks in triple-negative breast cancer. Cell Physiol Biochem 50: 473-488, 2018.

47. Song H, Li D, Wu T, Xie D, Hua K, Hu J, Deng X, Ji C, Deng Y and Fang L: MicroRNA-301b promotes cell proliferation and apoptosis resistance in triple-negative breast cancer by targeting CYLD. BMB Rep 51: 602-607, 2018.

48. Romero-Cordoba SL, Rodriguez-Cuevas S, Bautista-Pina V, Maffuz-Aziz A, D'Ippolito E, Cosentino G, Baroni S, Iorio MV and Hidalgo-Miranda A: Loss of function of miR-342-3p results in MCT1 over-expression and contributes to oncogenic metabolic reprogramming in triple negative breast cancer. Sci Rep 8: 12252, 2018.

49. Razaviyan J, Hadavi R, Tavakoli R, Kamani F, Paknejad M and Mohammadi YS: Expression of miRNAs targeting mTOR and S6K1 genes of mTOR signaling pathway including miR-96, miR-557, and miR-3182 in triple-negative breast cancer. Appl Biochem Biotechnol 186: 1074-1089, 2018.

50. García-Vázquez R, Marchat LA, Ruíz-García E, Astudillo-de la Vega H,Meneses-García A, Arce-Salinas C, Bargallo-Rocha E, Carlos-Reyes Á, López-González JS, Pérez-Plasencia C, et al: MicroRNA-143 is associated with pathological complete response and regulates multiple signaling proteins in breast cancer. Technol Cancer Res Treat 18: 1533033819827309, 2019.

51. Schwarzenbacher D, Klec C, Pasculli B, Cerk S Rinner B, Karbiener M, Ivan C, Barbano R, Ling H, WulfGoldenberg A, et al: MiR-1287-5p inhibits triple negative breast cancer growth by interaction with phosphoinositide 3-kinase CB thereby sensitizing cells for PI3Kinase inhibitors. Breast Cancer Res 21: 20, 2019.

52. Wang DY, Gendoo DMA, Ben-David Y, Woodgett JR and Zacksenhaus E: A subgroup of microRNAs defines PTEN-deficient, triple-negative breast cancer patients with poorest prognosis and alterations in RB1, MYC, and Wnt signaling. Breast Cancer Res 21: 18, 2019.

53. Cantini L, Bertoli G, Cava C, Dubois T, Zinovyev A, Caselle M, Castiglioni I, Barillot E and Martignetti L: Identification of microRNA clusters cooperatively acting on epithelial to mesenchymal transition in triple negative breast cancer. Nucleic Acids Res 47: 2205-2215, 2019.

54. Wong CK, Gromisch C, Ozturk S, Papageorgis P, Abdolmaleky HM, Reinhard BM, Thiagalingam A and Thiagalingam S: MicroRNA-4417 is a tumor suppressor and prognostic biomarker for triple-negative breast cancer. Cancer Biol Ther 20: 1113-1120, 2019 
55. Zhao Z, Li L, Du P, Ma L, Zhang W, Zheng L, Lan B, Zhang B, $\mathrm{Ma} \mathrm{F}, \mathrm{Xu} \mathrm{B}$, et al: Transcriptional downregulation of miR-4306 serves as a new therapeutic target for triple negative breast cancer. Theranostics 9: 1401-1416, 2019.

56. Wang C, Xu C, Niu R, Hu G, Gu Z and Zhuang Z: MiR-890 inhibits proliferation and invasion and induces apoptosis in triple-negative breast cancer cells by targeting CD147. BMC Cancer 19: 577, 2019.

57. Liang F, Fu X and Wang L: miR-5590-3p-YY1 feedback loop promotes the proliferation and migration of triple-negative breast cancer cells. J Cell Biochem 120: 18415-18424, 2019.

58. Wang X, Chen T, Zhang Y, Zhang N, Li C, Li Y, Liu Y, Zhang H, Zhao W, Chen B, et al: Long noncoding RNA Linc00339 promotes triple-negative breast cancer progression through miR-377-3p/HOXC6 signaling pathway. J Cell Physiol 234: 13303-13317, 2019.

59. Son D, Kim Y, Lim S, Kang HG, Kim DH, Park JW, Cheong W, Kong HK, Han W, Park WY, et al: miR-374a-5p promotes tumor progression by targeting ARRB1 in triple negative breast cancer. Cancer Lett 454: 224-233, 2019.

60. Tormo E, Ballester S, Adam-Artigues A, Burgués O, Alonso E, Bermejo B, Menéndez S, Zazo S, Madoz-Gúrpide J, Rovira A, et al: The miRNA-449 family mediates doxorubicin resistance in triple-negative breast cancer by regulating cell cycle factors. Sci Rep 9: 5316, 2019.

61. Shi P, Chen C, Li X, Wei Z, Liu Z and Liu Y: MicroRNA-124 suppresses cell proliferation and invasion of triple negative breast cancer cells by targeting STAT3. Mol Med Rep 19: 3667-3675, 2019.

62. Liu X, Wang J and Zhang G: miR-4458 regulates cell proliferation and apoptosis through targeting SOCS1 in triple-negative breast cancer. J Cell Biochem 120: 12943-12948, 2019.

63. Koduru SV, Tiwari AK, Leberfinger A, Hazard SW, Kawasawa YI, Mahajan M and Ravnic DJ: A comprehensive NGS data analysis of differentially regulated miRNAs, piRNAs, lncRNAs and sn/snoRNAs in triple negative breast cancer. J Cancer 8: 578-596, 2017.

64. Tang Q, Ouyang H, He D, Yu C and Tang G: MicroRNA-based potential diagnostic, prognostic and therapeutic applications in triple-negative breast cancer. Artif Cells Nanomed Biotechnol 47: 2800-2809, 2019.

65. Naorem LD, Muthaiyan M and Venkatesan A: Identification of dysregulated miRNAs in triple negative breast cancer: A meta-analysis approach. J Cell Physiol 234: 11768-11779, 2019.

66. Geyer FC, Lacroix-Triki M, Savage K, Arnedos M, Lambros MB, MacKay A, Natrajan R and Reis-Filho JS: $\beta$-catenin pathway activation in breast cancer is associated with triple-negative phenotype but not with CTNNB1 mutation. Mod Pathol 24 209-231, 2011

67. Loi S, Dushyanthen S, Beavis PA, Salgado R, Denkert C, Savas P, Combs S, Rimm DL, Giltnane JM, Estrada MV, et al RAS/MAPK activation is associated with reduced tumor infiltrating lymphocytes in triple negative breast cancer: Therapeutic cooperation between MEK and PD1/PDL1 immune checkpoint inhibitors. Clin Cancer Res 22: 1499-1509, 2016.

68. Piasecka D, Braun M, Kordek R, Sadej R and Romanska H: MicroRNAs in regulation of triple-negative breast cancer progression. J Cancer Res Clin Oncol 144: 1401-1411, 2018.

69. Blondal T, Jensby Nielsen S, Baker A, Andreasen D, Mouritzen P, Wrang TM and Dahlsveen IK: Assessing sample and miRNA profile quality in serum and plasma or other biofluids. Methods 59: S1-S6, 2013.

70. Hunter MP, Ismail N, Zhang X, Aguda BD, Lee EJ, Yu L, Xiao T, Schafer J, Lee ML, Schmittgen TD, et al: Detection of microRNA expression in human peripheral blood microvesicles. PLoS One 3: e3694, 2008.

71. Chim SSC, Shing TKF, Hung ECW, Leung TY, Lau TK, Chiu RW and Lo YM: Detection and characterization of placenta microRNAs in maternal plasma. Clin Chem 54: 482-490, 2008.

72. Yu X, Odenthal $\mathrm{M}$ and Fries JW: Exosomes as miRNA carriers: Formation-function-future. Int J Mol Sci 17: 2028, 2016.

73. Mitchell PS, Parkin RK, Kroh EM, Fritz BR, Wyman SK, Pogosova-Agadjanyan EL, Peterson A, Noteboom J, O'Briant KC Allen A, et al: Circulating microRNAs as stable blood-based markers for cancer detection. Proc Natl Acad Sci USA 105 10513-10518, 2008.

74. Ma R, Jiang T and Kang X: Circulating microRNAs in cancer: Origin, function and application. J Exp Clin Cancer Res 31: 38, 2012 .
75. Sahlberg K, Bottai G, Naume B, Burwinkel B, Calin GA, Børresen-Dale AL and Santarpia L: A serum microRNA signature predicts tumor relapse and survival in triple-negative breast cancer patients. Clin Cancer Res 21: 1207-1214, 2015.

76. Kahraman M, Röske A, Laufer T, Fehlmann T, Backes C, Kern F, Kohlhaas J, Schrörs H, Saiz A, Zabler C, et al: MicroRNA in diagnosis and therapy monitoring of early-stage triple-negative breast cancer. Sci Rep 8: 11584, 2018.

77. Braicu C, Raduly L, Morar-Bolba G, Cojocneanu R, Jurj A, Pop LA, Pileczki V, Ciocan C, Moldovan A, Irimie A, et al: Aberrant miRNAs expressed in HER-2 negative breast cancers patient. J Exp Clin Cancer Res 37: 257, 2018.

78. Madhavan D, Peng C, Wallwiener M, Zucknick M, Nees J, Schott S, Rudolph A, Riethdorf S, Trumpp A, Pantel K, et al: Circulating miRNAs with prognostic value in metastatic breast cancer and for early detection of metastasis. Carcinogenesis 37: 461-470, 2016

79. Heneghan HM, Miller N, Kelly R, Newell J and Kerin MJ: Systemic miRNA-195 differentiates breast cancer from other malignancies and is a potential biomarker for detecting noninvasive and early stage disease. Oncologist 15: 673-682, 2010.

80. Zeng RC, Zhang W, Yan XQ, Ye ZQ, Chen ED, Huang DP, Zhang XH and Huang GL: Down-regulation of miRNA-30a in human plasma is a novel marker for breast cancer. Med Oncol 30: 477, 2013.

81. Eichelser C, Flesch-Janys D, Chang-Claude J, Pantel K and Schwarzenbach H: Deregulated serum concentrations of circulating cell-free microRNAs miR-17, miR-34a, miR-155, and miR-373 in human breast cancer development and progression. Clin Chem 59: 1489-1496, 2013.

82. Eichelser C, Stückrath I, Müller V, Milde-Langosch K, Wikman H, Pantel K and Schwarzenbach H: Increased serum levels of circulating exosomal microRNA-373 in receptor-negative breast cancer patients. Oncotarget 5: 9650-9663, 2014.

83. Shin VY, Siu JM, Cheuk I, Ng EK and Kwong A: Circulating cell-free miRNAs as biomarker for triple-negative breast cancer. Br J Cancer 112: 1751-1759, 2015.

84. Mishra S, Srivastava AK, Suman S, Kumar V and Shukla Y: Circulating miRNAs revealed as surrogate molecular signatures for the early detection of breast cancer. Cancer Lett 369: 67-75, 2015.

85. Huo D, Clayton WM, Yoshimatsu TF, Chen J and Olopade OI: Identification of a circulating microRNA signature to distinguish recurrence in breast cancer patients. Oncotarget 7: 55231-55248, 2016.

86. Chen J, Shin VY, Siu MT, Ho JC, Cheuk I and Kwong A: miR-199a-5p confers tumor-suppressive role in triple-negative breast cancer. BMC Cancer 16: 887, 2016.

87. Gao S, Wang Y, Wang M, Li Z, Zhao Z, Wang RX, Wu R, Yuan Z, Cui R, Jiao K, et al: MicroRNA-155, induced by FOXP3 through transcriptional repression of BRCA1, is associated with tumor initiation in human breast cancer. Oncotarget 8: 41451-41464, 2017.

88. Zeng Z, Chen X, Zhu D, Luo Z and Yang M: Low expression of circulating MicroRNA-34c is associated with poor prognosis in triple-negative breast cancer. Yonsei Med J 58: 697-702, 2017.

89. Qattan A, Intabli H, Alkhayal W, Eltabache C, Tweigieri T and Amer SB: Robust expression of tumor suppressor miRNA's let-7 and miR-195 detected in plasma of Saudi female breast cancer patients. BMC Cancer 17: 799, 2017.

90. Swellam M, Mahmoud MS, Hashim M, Hassan NM, Sobeih ME and Nageeb AM: Clinical aspects of circulating miRNA-335 in breast cancer patients: A prospective study. J Cell Biochem 120: 8975-8982, 2019

91. Niedźwiecki S, Piekarski J, Szymańska B, Pawłowska Z and Jeziorski A: Serum levels of circulating miRNA-21, miRNA-10b and miRNA-200c in triple-negative breast cancer patients. Ginekol Pol 89: 415-420, 2018.

92. Bai X, Han G, Liu Y, Jiang H and He Q: MiRNA-20a-5p promotes the growth of triple-negative breast cancer cells through targeting RUNX3. Biomed Pharmacother 103: 1482-1489, 2018.

93. Gorer PA: Some recent work on tumor immunity. Adv Cancer Res 4: 149-186, 1956.

94. Barrette M: Some observations on the nature of the 'antigen' in 'tumor immunity'. Acta Unio Int Contra Cancrum 15: 940-942, 1959.

95. Zilber LA: Specific tumor antigens. Adv Cancer Res 5: 291-329, 1958.

96. Klein E, Becker S, Svedmyr E, Jondal M and Vánky F: Tumor infiltrating lymphocytes. Ann N Y Acad Sci 276: 207-216, 1976. 
97. Richters A and Kaspersky CL: Surface immunoglobulin positive lymphocytes in human breast cancer tissue and homolateral axillary lymph nodes. Cancer 35: 129-133, 1975.

98. Svennevig JL, Lövik M and Svaar H: Isolation and characterization of lymphocytes and macrophages from solid, malignant human tumours. Int J Cancer 23: 626-631, 1979.

99. Hanahan D and Weinberg RA: Hallmarks of cancer: The next generation. Cell 144: 646-674, 2011.

100. Conforti F, Pala L, Bagnardi V, De Pas T, Martinetti M, Viale G, Gelber RD and Goldhirsch A: Cancer immunotherapy efficacy and patients' sex: A systematic review and meta-analysis. Lancet Oncol 19: 737-746, 2018.

101. Galon J, Pagès F, Marincola FM, Angell HK, Thurin M, Lugli A, Zlobec I, Berger A, Bifulco C, Botti G, et al: Cancer classification using the Immunoscore: A worldwide task force. J Transl Med 10: 205, 2012.

102. Salgado R, Denkert C, Demaria S, Sirtaine N, Klauschen F, Pruneri G, Wienert S, Van den Eynden G, Baehner FL, Penault-Llorca F, et al: The evaluation of tumor-infiltrating lymphocytes (TILs) in breast cancer: Recommendations by an international TILs working group 2014. Ann Oncol 26: 259-271, 2015.

103. Denkert C, Loibl S, Noske A, Roller M, Müller BM, Komor M, Budczies J, Darb-Esfahani S, Kronenwett R, Hanusch C, et al: Tumor-associated lymphocytes as an independent predictor of response to neoadjuvant chemotherapy in breast cancer. J Clin Oncol 28: 105-113, 2010.

104. Ibrahim EM, Al-Foheidi ME, Al-Mansour MM and Kazkaz GA: The prognostic value of tumor-infiltrating lymphocytes in triple-negative breast cancer: A meta-analysis. Breast Cancer Res Treat 148: 467-476, 2014.

105. Adams S, Gray RJ, Demaria S, Goldstein L, Perez EA, Shulman LN, Martino S, Wang M, Jones VE, Saphner TJ, et al: Prognostic value of tumor-infiltrating lymphocytes in triple-negative breast cancers from two phase III randomized adjuvant breast cancer trials: ECOG 2197 and ECOG 1199. J Clin Oncol 32: 2959-2966, 2014.

106. Ruan M, Tian T, Rao J, Xu X, Yu B, Yang W and Shui R: Predictive value of tumor-infiltrating lymphocytes to pathological complete response in neoadjuvant treated triple-negative breast cancers. Diagn Pathol 13: 66, 2018.

107. Denkert C, von Minckwitz G, Brase JC, Sinn BV, Gade S, Kronenwett R, Pfitzner BM, Salat C, Loi S, Schmitt WD, et al: Tumor-infiltrating lymphocytes and response to neoadjuvant chemotherapy with or without carboplatin in human epidermal growth factor receptor 2-positive and triple-negative primary breast cancers. J Clin Oncol 33: 983-991, 2015.

108. Poggio F, Bruzzone M, Ceppi M, Pondé NF, La Valle G, Del Mastro L, de Azambuja E and Lambertini M: Platinum-based neoadjuvant chemotherapy in triple-negative breast cancer: A systematic review and meta-analysis. Ann Oncol 29: 1497-1508, 2018.

109. Karn T, Pusztai L, Rody A, Holtrich U and Becker S: The influence of host factors on the prognosis of breast cancer: Stroma and immune cell components as cancer biomarkers. Curr Cancer Drug targets 15: 652-664, 2015.
110. Bertucci F, Finetti P, Cervera N, Charafe-Jauffret E, Mamessier E, Adélaïde J, Debono S, Houvenaeghel G, Maraninchi D, Viens $\mathrm{P}$, et al: Gene expression profiling shows medullary breast cancer is a subgroup of basal breast cancers. Cancer Res 66: 4636-4644, 2006.

111. Nathan MR and Schmid P: The emerging world of breast cancer immunotherapy. Breast 37: 200-206, 2018.

112. U.S. Food and Drug Administration: FDA Approves Atezolizumab For PD-L1 Positive Unresectable Locally Adva. https://www.fda.gov/drugs/drug-approvals-and-databases/fdaapproves-atezolizumab-pd-11-positive-unresectable-locallyadvanced-or-metastatic-triple-negative. Accessed August 17, 2020.

113. Brockwell NK, Owen KL, Zanker D, Spurling A, Rautela J, Duivenvoorden HM, Baschuk N, Caramia F, Loi S, Darcy PK, et al: Neoadjuvant Interferons: Critical for effective PD-1-based immunotherapy in TNBC. Cancer Immunol Res 5: 871-884, 2017.

114. Romano G and Kwong LN: Diagnostic and therapeutic applications of miRNA-based strategies to cancer immunotherapy. Cancer Metastasis Rev 37: 45-53, 2018.

115. Kamimura N, Wolf AM and Iwai Y: Development of CANCER IMMUNOTHERAPY TARGeting the PD-1 pathway. J Nippon Med Sch 86: 10-14, 2019.

116. Bally AP, Austin JW and Boss JM: Genetic and epigenetic regulation of PD-1 expression. J Immunol 196: 2431-2437, 2016.

117. Wei R, Guo L, Wang Q, Miao J, Kwok HF and Yao Lin: Targeting PD-L1 protein: Translation, modification and transport. Curr Protein Pept Sci 20: 82-91, 2019.

118. Yee D, Shah KM, Coles MC, Sharp TV and Lagos D: MicroRNA-155 induction via TNF- $\alpha$ and IFN- $\gamma$ suppresses expression of programmed death ligand-1 (PD-L1) in human primary cells. J Biol Chem 292: 20683-20693, 2017.

119. Fan T, Mao Y, Sun Q, Liu F, Lin JS, Liu Y, Cui J and Jiang Y: Branched rolling circle amplification method for measuring serum circulating microRNA levels for early breast cancer detection. Cancer Sci 109: 2897-2906, 2018.

120. Ling V, Wu PW, Finnerty HF, Sharpe AH, Gray GS and Collins M: Complete sequence determination of the mouse and human CTLA4 gene loci: Cross-species DNA sequence similarity beyond exon borders. Genomics 60: 341-355, 1999.

121. Rowshanravan B, Halliday N and Sansom DM: CTLA-4: A moving target in immunotherapy. Blood 131: 58-67, 2018.

122. Chikuma S: CTLA-4, an essential immune-checkpoint for T-cell activation. In: Emerging Concepts Targeting Immune Checkpoints in Cancer and Autoimmunity. Current Topics in Microbiology and Immunology. Yoshimura A (ed). Springer, pp99-126, 2017. https://www.springer.com/gp/ book/9783319689289. International (CC BY-NC-ND 4.0) License. 